\title{
Tomography of the 2011 Iwaki earthquake (M 7.0) and Fukushima nuclear power plant area
}

\author{
P. Tong ${ }^{1,2}$, D. Zhao ${ }^{1}$, and D. Yang ${ }^{2}$ \\ ${ }^{1}$ Department of Geophysics, Tohoku University, Sendai 980-8578, Japan \\ ${ }^{2}$ Department of Mathematical Sciences, Tsinghua University, Beijing, China \\ Correspondence to: P. Tong (tongping85@gmail.com), D. Zhao (zhao@aob.gp.tohoku.ac.jp)
}

Received: 12 December 2011 - Published in Solid Earth Discuss.: 22 December 2011

Revised: 2 February 2012 - Accepted: 6 February 2012 - Published: 14 February 2012

\begin{abstract}
High-resolution tomographic images of the crust and upper mantle in and around the area of the 2011 Iwaki earthquake (M 7.0) and the Fukushima nuclear power plant are determined by inverting a large number of high-quality arrival times with both the finite-frequency and ray tomography methods. The Iwaki earthquake and its aftershocks mainly occurred in a boundary zone with strong variations in seismic velocity and Poisson's ratio. Prominent lowvelocity and high Poisson's ratio zones are revealed under the Iwaki source area and the Fukushima nuclear power plant, which may reflect fluids released from the dehydration of the subducting Pacific slab under Northeast Japan. The 2011 Tohoku-oki earthquake (Mw 9.0) caused static stress transfer in the overriding Okhotsk plate, resulting in the seismicity in the Iwaki source area that significantly increased immediately following the Tohoku-oki mainshock. Our results suggest that the Iwaki earthquake was triggered by the ascending fluids from the Pacific slab dehydration and the stress variation induced by the Tohoku-oki mainshock. The similar structures under the Iwaki source area and the Fukushima nuclear power plant suggest that the security of the nuclear power plant site should be strengthened to withstand potential large earthquakes in the future.
\end{abstract}

\section{Introduction}

The subduction of the Pacific plate beneath the Okhotsk plate causes intense seismicity in the Northeastern (NE) Japan arc. The great Tohoku-oki earthquake (Mw 9.0) occurred on 11 March 2011 in the NE Japan forearc region and it was the largest recorded earthquake ever to hit Japan (Fig. 1a). It has caused large variations in stress field not only near the source zone but also in regions far away from the epicenter, and so the seismic activity in the crust of the overriding plate west of the source area has increased significantly after the Tohokuoki mainshock that ruptured the megathrust zone beneath the Pacific Ocean (Okada et al., 2011).

The Iwaki earthquake (M 7.0) occurred in a previous seismicity gap on 11 April 2011 and it was one of the major aftershocks following the Tohoku-oki mainshock and the strongest one hit the Japan land area. This large crustal earthquake occurred at a depth of $6.4 \mathrm{~km}$ and was located about $200 \mathrm{~km}$ southwest of the Tohoku-oki mainshock. It was caused by normal faulting with some strike-slip component along the Idosawa fault (Fig. 1b). About 11-km long coseismic surface ruptures were recognized along the Idosawa fault, which are interpreted as a surface manifestation of the fault reactivation associated with the normal faulting event (http://en.wikipedia.org/wiki/April_2011_ Fukushima_earthquake). This normal-faulting earthquake is in contrast to the compressional stress regime in NE Japan and may reflect enhanced extensional stress on the overriding block induced by the Tohoku-oki mainshock (Ishiyama et al., 2011). The variations in stress field give rise to high seismicity in the area where the 2011 Iwaki earthquake took place. In the area (inset blue box in Fig. 1b), there were only 1215 crustal events recorded by the dense Japanese seismic network during 3 June 2002 to 11 March 2011, whereas the number was increased to 24108 following the Tohoku-oki mainshock till 27 October 2011, including 23 crustal earthquakes with $\mathrm{M} \geq 5.0$ (Fig. 1b).

The disabled Fukushima nuclear power plant (FNPP), which has suffered major damage from the Tohoku-oki earthquake and the subsequent tsunami, is located about $60 \mathrm{~km}$ northeast of the Iwaki earthquake epicenter (Fig. 1). The 

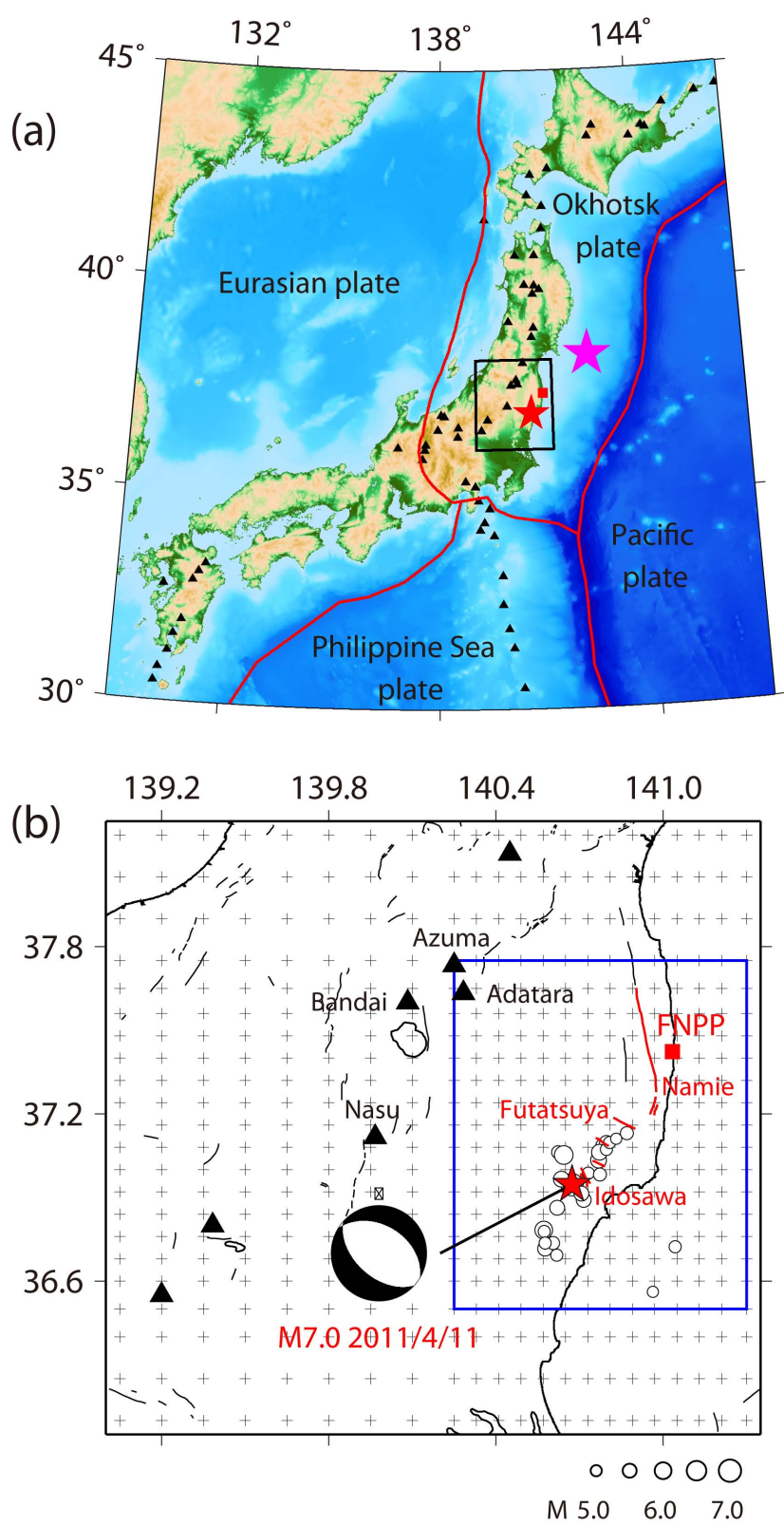

Fig. 1. (a) The surface topography and tectonic setting in and around the Japan Islands. The black box shows the present study area enlarged in (b). The purple star represents the great Tohokuoki earthquake (Mw 9.0) on 11 March 2011. The red lines show the major plate boundaries. (b) The present study area. The blue box shows the area where the 2011 Iwaki earthquake (M 7.0) occurred and the Fukushima nuclear power plant is located. The open circles show the relatively large aftershocks $(M>5.0)$ of the Iwaki earthquake. The curved red and black lines denote the active faults. The grey crosses represent the grid nodes set up for the tomographic inversion. The red star and square in (b) denote the Iwaki earthquake epicenter and the Fukushima nuclear power plant (FNPP), respectively. The black triangles indicate the active arc volcanoes. consequent Fukushima nuclear disaster has captured the world's attention and is already influencing the future development and usage of nuclear power. It has posed serious challenges regarding the security, site selection and design critique of nuclear power plants, especially in seismically active regions. Because FNPP is located close to the Iwaki source area, it is necessary and important to investigate the genesis of the Iwaki earthquake and seismotectonics of the region.

Seismic tomography is a powerful tool to map out structural heterogeneities in the crust and upper mantle. The increased seismicity and the dense seismic network in and around the Iwaki source area provide us with a valuable data set for studying the crust and upper mantle structure in this area, which may improve our understanding of seismotectonics and subduction dynamics. In addition, the results will provide important information on the FNPP site security, which will prove useful for reviewing seismic safety of the existing nuclear plants and other nuclear facilities on the Japan Islands.

\section{Data and method}

In this study, we used a large number of $\mathrm{P}$ and $\mathrm{S}$ wave arrival-time data from 6506 earthquakes during a period from June 2002 to October 2011, which were recorded by the combined seismic network in Japan (known as the JMA Unified Catalogue) (Zhao et al., 2011) including the HighSensitivity Seismic Network, Japan Meteorological Agency (JMA) Seismic Network, and the Japan National University Seismic Network (Fig. 2). These earthquakes were carefully selected based on the following criteria: (1) all the events $(\mathrm{M}>1.5)$ were recorded by more than 30 seismic stations; (2) to keep a uniform distribution of hypocenter locations and avoid the event clustering, we divide the study area (the blue box in Fig. 1b) into $3 \mathrm{~km} \times 3 \mathrm{~km} \times 0.75 \mathrm{~km}$ blocks and divide the surrounding region (outside of the blue box) into $12 \mathrm{~km} \times 12 \mathrm{~km} \times 3 \mathrm{~km}$ blocks, and we selected only one event in each block that was recorded by the maximal number of stations; (3) both shallow and intermediate-depth events are selected; (4) the uncertainty in the hypocentral location is $<4.0 \mathrm{~km}$. As a result, 6506 events were selected that were recorded by 132 seismic stations in the study area (Fig. 2). These events generated $199363 \mathrm{P}$-wave and $184919 \mathrm{~S}$-wave arrival times that were used in the tomographic inversions.

To conduct the tomographic inversion, we set up grid nodes in the study area (Fig. 1b). The horizontal grid interval is $0.08^{\circ}$ in the Iwaki earthquake and FNPP area (the blue box in Fig. $1 b$ ) and $0.15^{\circ}$ in the surrounding region. The vertical grid interval is $5-10 \mathrm{~km}$ in the crust and $20-30 \mathrm{~km}$ in the upper mantle. Following the previous tomographic studies of the NE Japan arc (e.g., Zhao et al., 1992, 2011; Huang et al., 2011), the starting velocity model contains the subducting Pacific slab that has $\mathrm{P}$ and $\mathrm{S}$ wave velocities $4 \%$ faster 

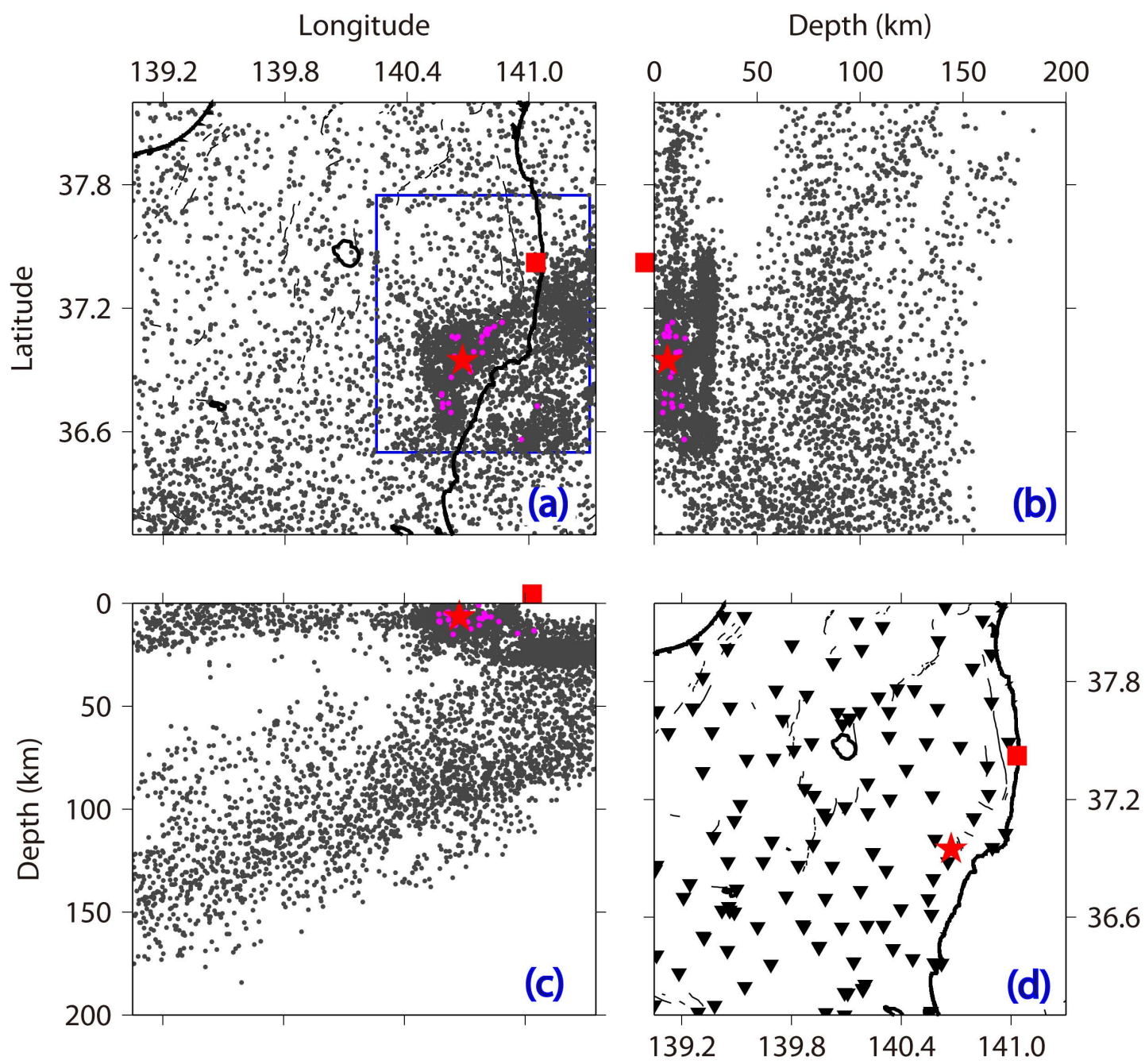

Fig. 2. (a-c) Hypocentral distribution of the 6506 earthquakes (gray dots) used in this study. The blue box in (a) indicates the area where the 2011 M 7.0 Iwaki earthquake (red star) occurred and the Fukushima nuclear power plant (red square) is located. The purple dots denote the relatively large aftershocks $(M>5.0)$ of the Iwaki earthquake. (d) Distribution of the 132 seismic stations (black inverse triangle) used in this study.

than those of the normal mantle, and the depth variations of the Conrad and Moho discontinuities and the upper boundary of the subducting Pacific slab are taken into account in the model parameterization.

We employed the ray and finite-frequency tomography methods (Zhao et al., 1992; Tong et al., 2011) to determine the 3-D seismic velocity structure in the study area. Hypocenter parameters and 3-D velocity variations were obtained simultaneously. After the Vp and Vs images were determined, the Poisson's ratio $(\sigma)$ image was determined using the relation $\left(V_{P} / V_{S}\right)^{2}=2(1-\sigma) /(1-2 \sigma)$ (Zhao et al., 1996). To obtain a reliable Poisson's ratio result, it is important to determine both $\mathrm{Vp}$ and $\mathrm{Vs}$ structures precisely. In this work we used nearly the same amount of $\mathrm{P}$ and $\mathrm{S}$ wave data in the inversion, and so the ray path coverage is almost the same for both $\mathrm{Vp}$ and Vs models. Therefore the amplitudes of velocity anomalies are well recovered for both $\mathrm{Vp}$ and Vs structures, which results in a reliable image of Poisson's ratio. To show the effectiveness of the two tomographic methods and make a valid comparison, we adopted the same grid, data set and damping and smoothing regularizations for both the finite-frequency and ray tomographic inversions. The optimal damping and smoothing parameters are determined from detailed analyses of the trade-off between the data variance reduction and the model smoothness for both $\mathrm{Vp}$ and the Vs models. The optimal regularization parameters are found to be almost the same for the ray and finite-frequency inversions. The damping and smoothing parameters are 5.0 and 0.1 for the $\mathrm{Vp}$ inversion, and they are 6.0 and 0.1 for the Vs inversion. 


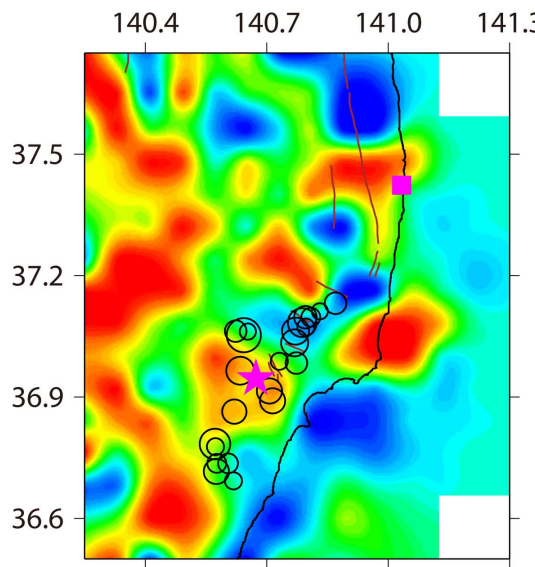

(a) $6 \mathrm{~km}$

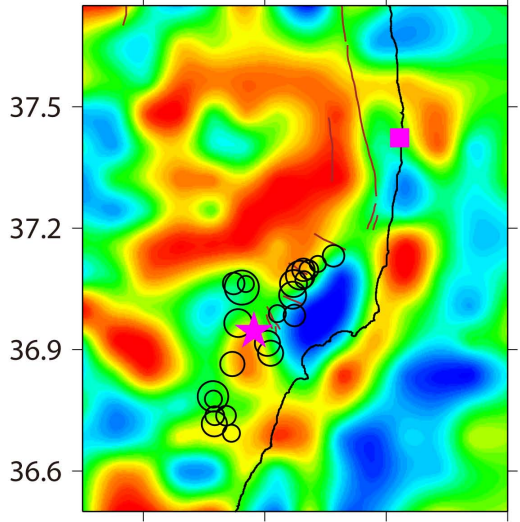

(c) $20 \mathrm{~km}$

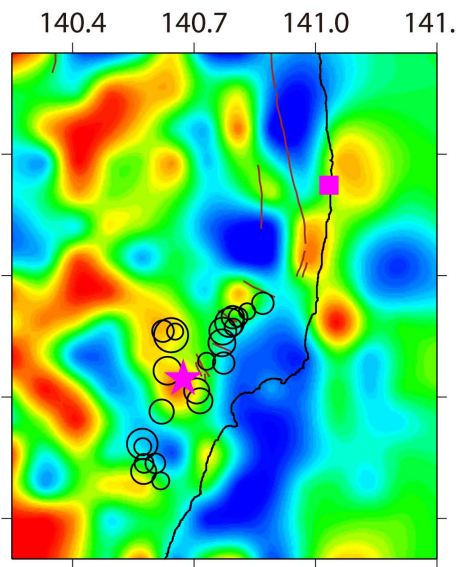

(b) $12 \mathrm{~km}$

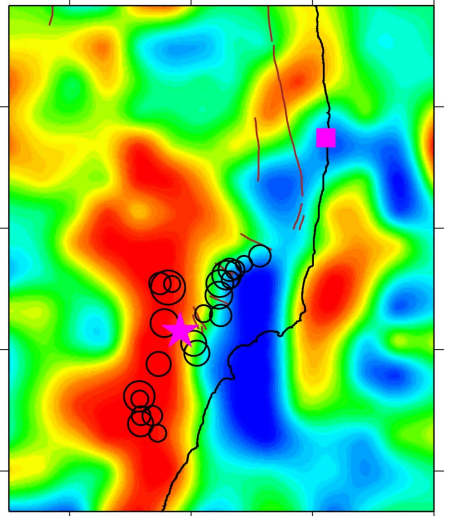

(d) $30 \mathrm{~km}$
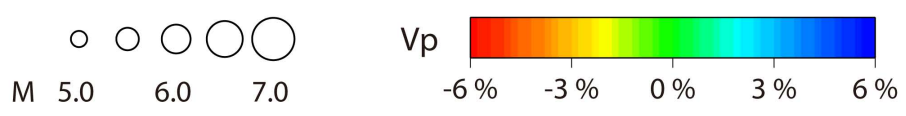

Fig. 3. Map views of the finite-frequency P-wave tomography in the crust under the Iwaki earthquake and Fukushima nuclear power plant area. The layer depth is shown below each map. Red and blue colors denote low and high velocities, respectively. The velocity perturbation (in \%) scale is shown at the bottom. The brown lines denote the active faults.

\section{Resolution and tomographic results}

We made detailed resolution analyses to assess the reliability of the tomographic results (see Figs. S1-S8 in the auxiliary material). We also adopted the structural similarity (SSIM) index defined by Tong et al. (2011) to compare the synthetic model and the inverted model quantitatively. These results indicate that our data set can well resolve the 3-D velocity structure and both the finite-frequency and ray tomography methods have a similar satisfactory performance in recovering the velocity anomalies (see Table S1 in the auxiliary material). The 3-D crustal velocity model in the Iwaki earthquake and FNPP area was determined reliably with a resolution of $8-10 \mathrm{~km}$, while in the surrounding area the resolution scale is $15-30 \mathrm{~km}$ in the crust and upper mantle.
Large Vp and Vs variations up to $6 \%$ and Poisson's ratio $(\sigma)$ variation of up to $10 \%$ are revealed in the study area (Figs. 3-5). Map views of the tomographic results indicate that strong lateral heterogeneities exist in the present study area (Figs. 3 and 4). The Iwaki earthquake and its aftershocks mainly occurred in a boundary zone with strong variations in seismic velocity and Poisson's ratio (Figs. 3-5). In the source zone of the 2011 Iwaki earthquake, a prominent low-Vp anomaly exists in the upper crust and it extends down to the lower crust and uppermost mantle, whereas lowVs and high- $\sigma$ are visible in the lower crust and uppermost mantle under the hypocenters of the Iwaki mainshock and major aftershocks (Fig. 5a-f). Interestingly, a low-Vp, lowVs and high- $\sigma$ anomaly exists in the crust beneath FNPP, and the low-velocity (low-V) zone extends down to the uppermost mantle (Fig. 5g-i). Low-V anomalies are revealed clearly in the crust and upper-mantle wedge under the active 


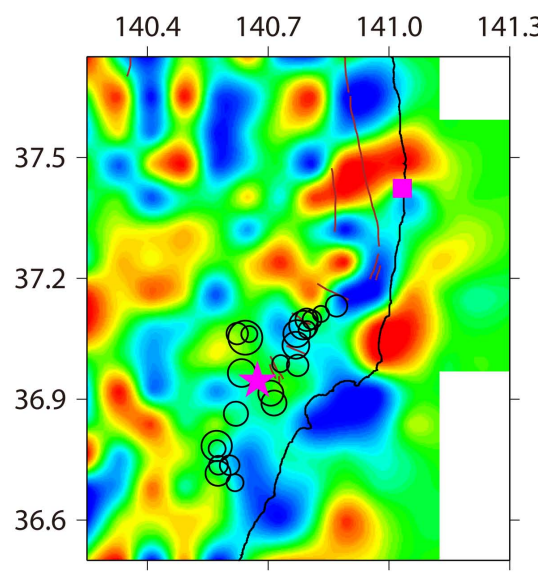

(a) $6 \mathrm{~km}$

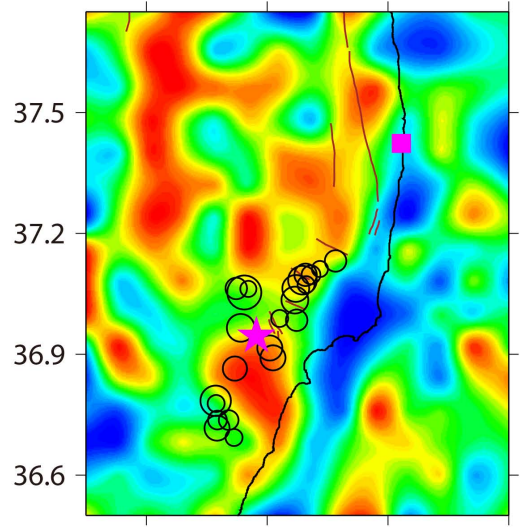

(c) $20 \mathrm{~km}$

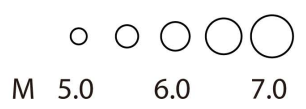

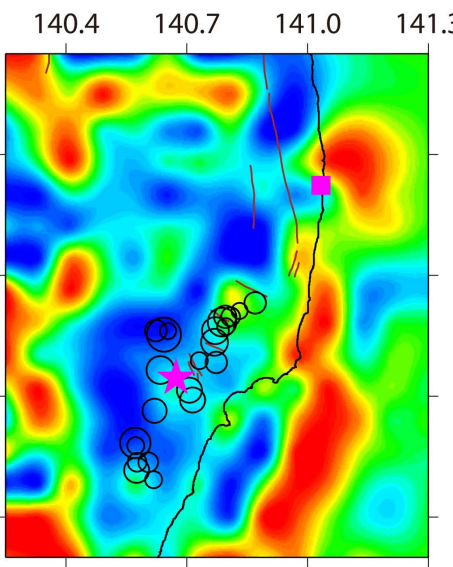

(b) $12 \mathrm{~km}$

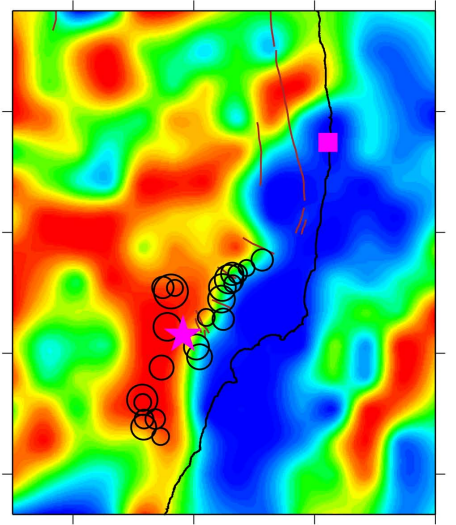

(d) $30 \mathrm{~km}$

141.3

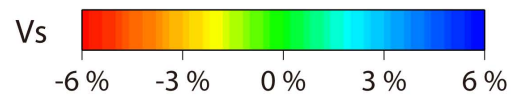

Fig. 4. The same as Fig. 3 but for the finite-frequency S-wave tomography.

arc volcanoes in the study area (Fig. 6), which reflect arc magmas caused by fluids from the slab dehydration and corner flow in the mantle wedge (e.g., Hasegawa and Zhao, 1994; Zhao et al., 1992; Huang et al., 2011). Under the Iwaki hypocenter, a low- $\mathrm{Vp}$ zone is visible in the lower crust and upper-mantle wedge and it extends down to the top of the subducting Pacific slab (Fig. 6a). A thin, vertical low-V anomaly exists in the lower crust and upper mantle beneath FNPP, and the anomaly is connected with the Pacific slab (Fig. 6b, d).

The overall patterns of velocity variations revealed by the finite-frequency and ray tomographic inversions are the same, except that the finite-frequency tomography generates slightly larger amplitudes of velocity perturbations. The structural similarity (SSIM) indices between the ray and finite-frequency models are greater than $93 \%$ for all the depth levels, which quantitatively demonstrates the consistency of the two models (Table S2).

\section{Discussion and conclusions}

Following the 2011 Tohoku-oki mainshock, normal-faulttype aftershocks occurred widely in the overriding plate due to a tensional stress change caused by the mainshock coseismic slip (Asano et al., 2011). A comparison of the focal mechanisms recorded before and after the 2011 Tohokuoki earthquake suggests that the stress field changed abruptly from horizontal compression to extension in the Iwaki source area (Kato et al., 2011). Imanishi et al. (2011) estimated that the E-W extensional stress with a few MPa was exerted to the study area and argued that the stress changes alone could not trigger this normal-faulting earthquake sequence. The Idosawa fault where the Iwaki earthquake occurred is a pre-existing normal dip-slip fault (http://riodb02.ibase.aist. go.jp/activefault/index_e.html). An effective mechanism to weaken the strength of this fault should be considered in discussing the factors that affected the initiation of the Iwaki earthquake and its aftershocks. One mechanism of reducing the fault strength is the existence of crustal fluids. 


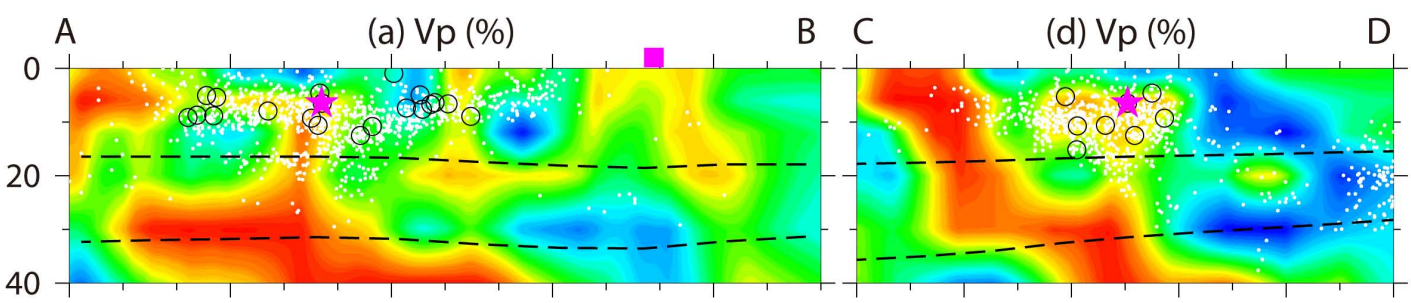

(b) $\mathrm{Vs}(\%)$

(e) Vs (\%)
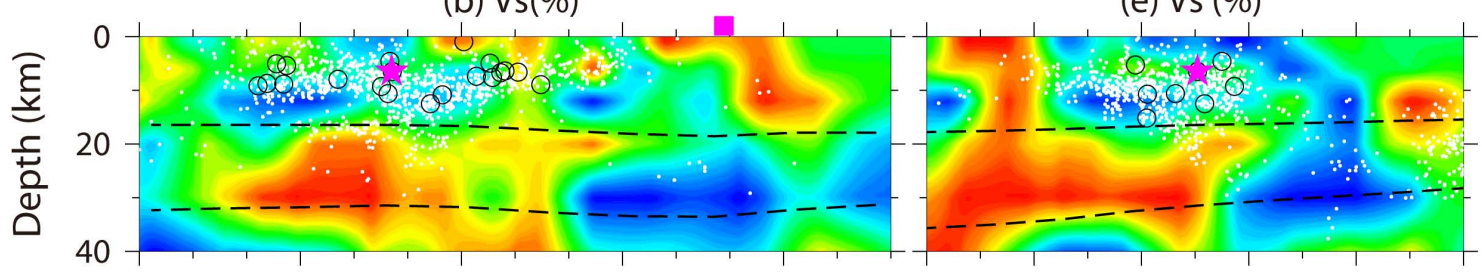

(c) $\sigma(\%)$

(f) $\sigma(\%)$

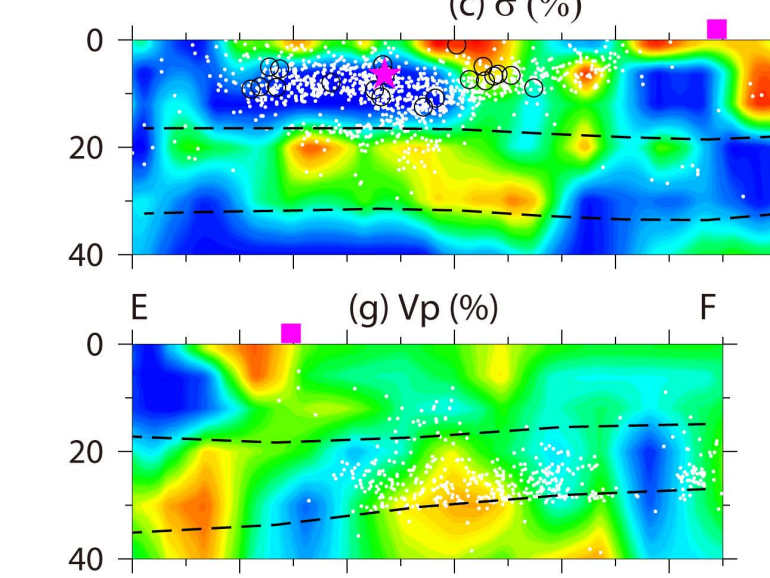

(h) Vs (\%)

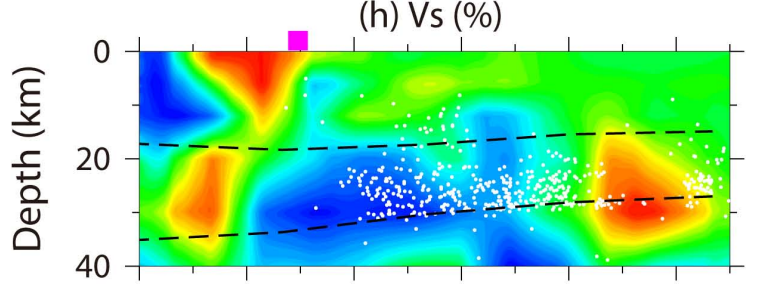

(i) $\sigma(\%)$
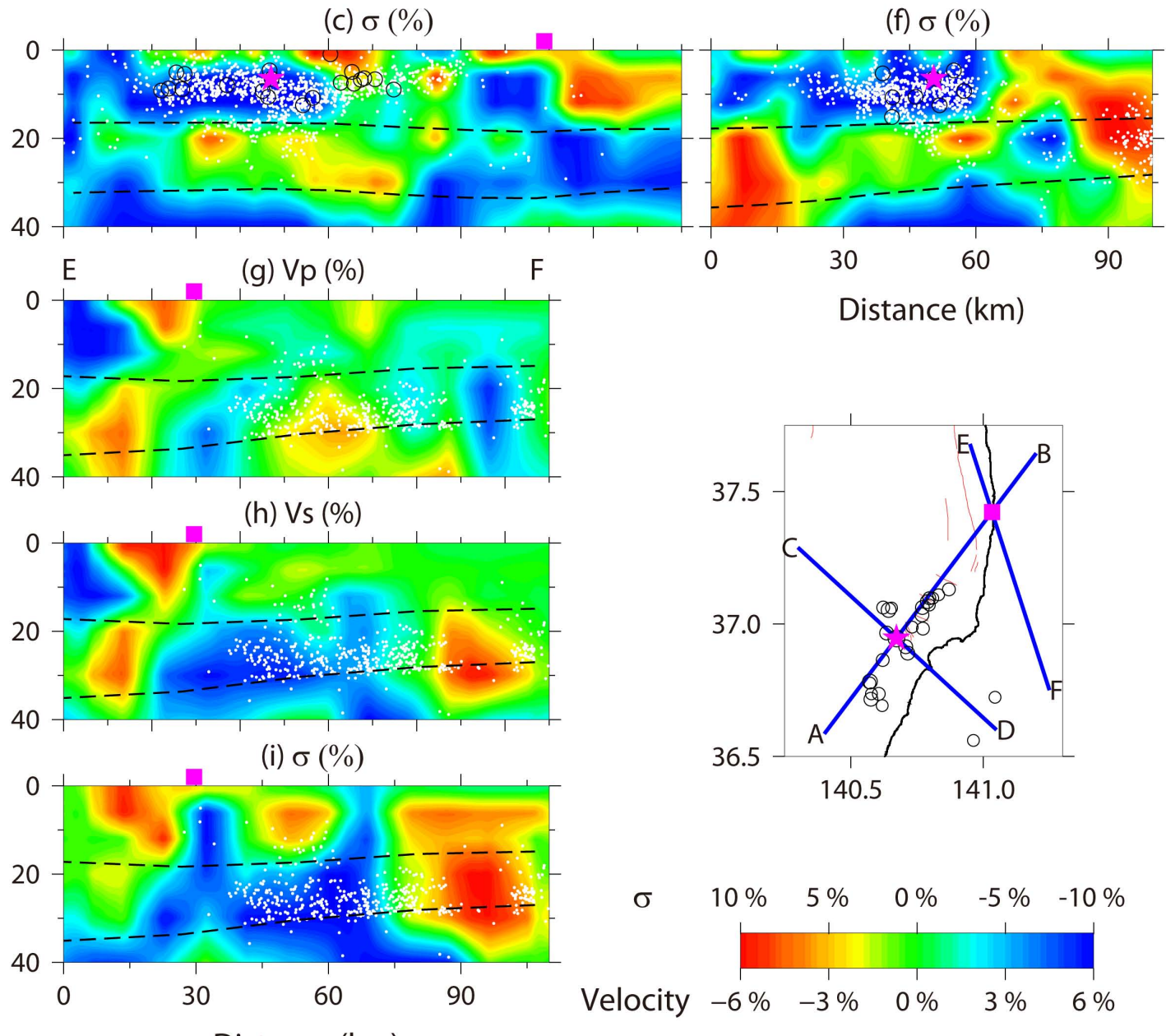

Distance $(\mathrm{km})$

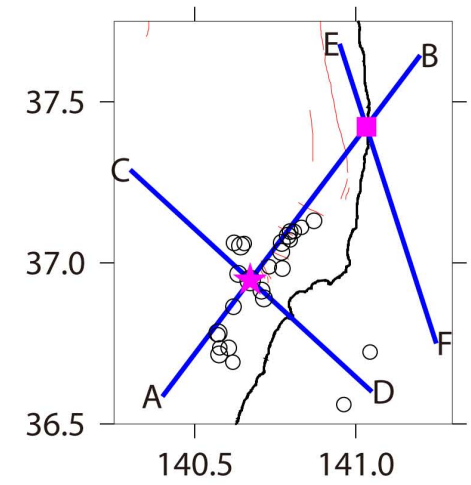

$\sigma \quad 10 \% \quad 5 \% \quad 0 \% \quad-5 \% \quad-10 \%$

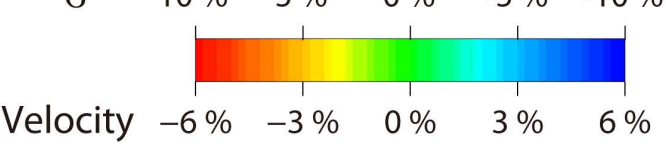

Distance $(\mathrm{km})$

Fig. 5. Vertical cross-sections of $P$ wave velocity, $S$ wave velocity, and Poisson's ratio images obtained with the finite-frequency tomography method along the lines $\mathrm{AB}(\mathbf{a}-\mathbf{c}), \mathrm{CD}(\mathbf{d}-\mathbf{f})$ and $\mathrm{EF}(\mathbf{g}-\mathbf{i})$ as shown on the inset map. The vertical exaggeration is 1:1. Small white dots denote the events (most are the aftershocks of the Iwaki earthquake) during 11 March 2011 to 27 October 2011, which are located within 8-km width along each profile. The star symbols denote the Iwaki mainshock (M 7.0) hypocenter at $6.4 \mathrm{~km}$ depth, while the open circles show the relatively large Iwaki aftershocks $(M>5.0)$. The square symbols represent the Fukushima nuclear power plant. The two dashed lines denote the Conrad and Moho discontinuities. Red color denotes low velocity and high Poisson's ratio, while blue color represents high velocity and low Poisson's ratio. The scales for the velocity and Poisson's ratio perturbations (in \%) are shown at the bottom. 

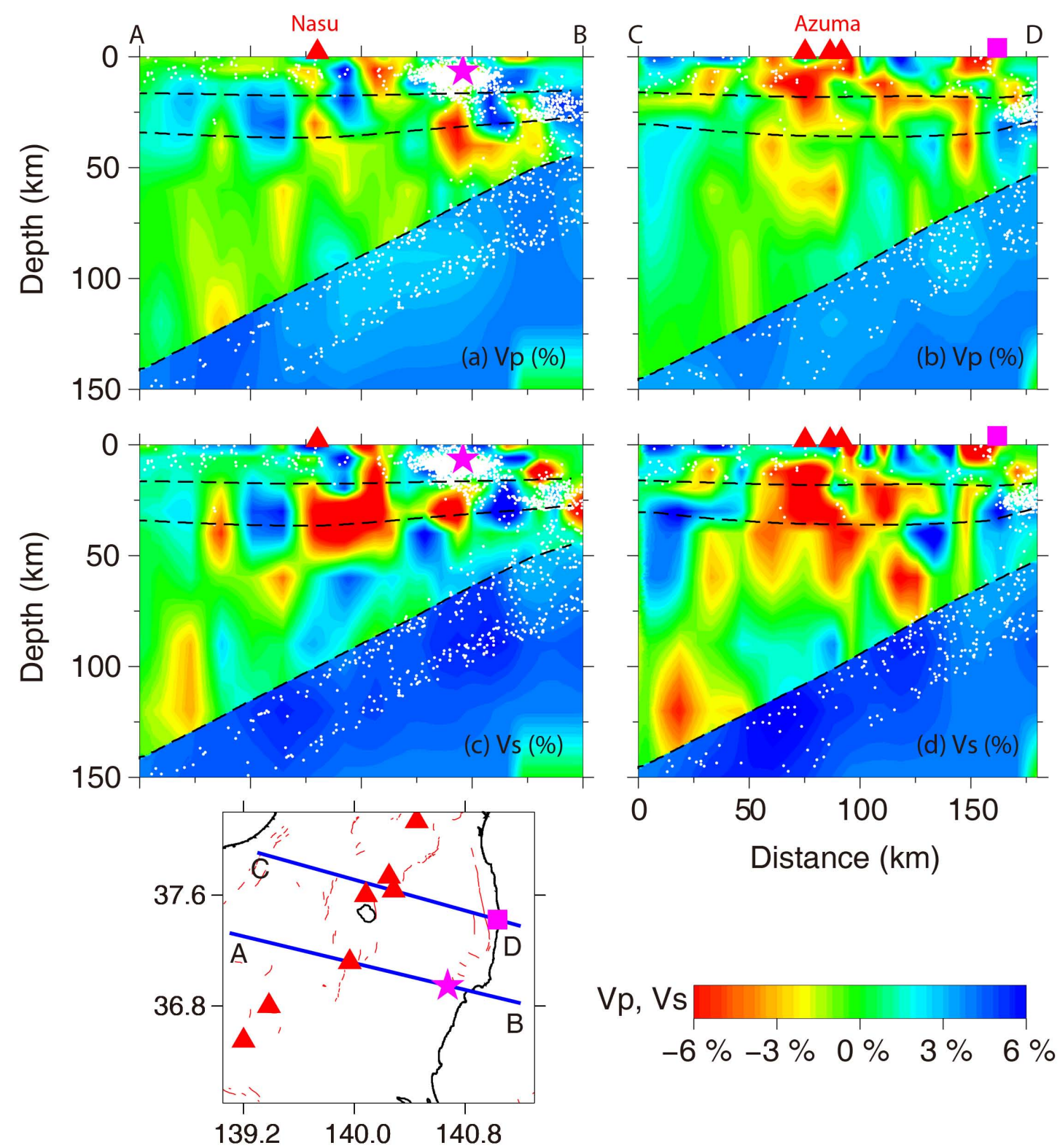

Fig. 6. Vertical cross-sections of (a, b) P-wave and (c, d) S-wave velocity images obtained with the finite-frequency tomography method along the profiles $\mathrm{AB}$ and $\mathrm{CD}$ as shown on the inset map. The vertical exaggeration is $1: 1$. Small white dots denote the events during 3 June 2002 to 27 October 2011, which are located within 20-km width along each profile. The purple star and square symbols denote the 2011 Iwaki mainshock (M 7.0) hypocenter and the Fukushima nuclear power plant, respectively. The red triangles represent the active volcanoes. The three dashed lines denote the Conrad and Moho discontinuities and the upper boundary of the subducting Pacific slab. Red and blue colors denote low and high velocities, respectively. The velocity perturbation (in \%) scale is shown at the bottom.

In this work we determined detailed tomographic images in the Iwaki earthquake and FNPP area using both the finitefrequency and ray tomography methods. This was achieved because of the availability of large amount of aftershock data recorded by the dense seismic network in Japan. The tomographic results generated by the finite-frequency and ray tomography methods are essentially the same, which is quantitatively verified by the SSIM indices. In and around the Iwaki earthquake area, significant low- $\mathrm{V}$ and high- $\sigma$ anomalies are revealed in the crust and upper mantle (Figs. 3-6). Because the Iwaki earthquake occurred in the NE Japan forearc and about $70 \mathrm{~km}$ away from the volcanic front (Fig. 1), the low-V and high- $\sigma$ anomaly may not represent arc magma but crustal fluids that affected the rupture nucleation, similar to the seismogenic process that happened in the source area of the 1995 Kobe earthquake (Zhao et al., 1996, 2010; Salah and Zhao, 
2003; Tong et al., 2011). As the Pacific plate subducts, the temperature and pressure in the subducting slab gradually increase, causing hydrated minerals within the slab to undergo dehydration decomposition. This process generates aqueous fluids which are less dense than the surrounding rock and so can migrate upward. In the forearc region, the fluids can move up to the overlying crust. When the fluids enter an active fault (such as the Idosawa fault) in the crust, fault-zone frictions will decrease. This process, together with the exertion of horizontally extensional stress regime, induced by the Tohoku-oki mainshock, caused reactivation of the Idosawa normal fault, leading to the 2011 Iwaki earthquake and its aftershocks. Previous studies have found that crustal fluids were involved in several large crustal earthquakes in the Japan Islands (e.g., Wang and Zhao, 2006a, b; Gupta et al., 2009; Zhao et al., 2010; Cheng et al., 2011; Padhy et al., 2011). It was suggested that fluids also affected the nucleation of large interplate earthquakes in the megathrust zone, such as the 2011 Tohoku-oki earthquake sequence (Zhao et al., 2011).

The low-V zones in the uppermost mantle under the volcanic front and back-arc areas (Fig. 6) are the manifestation of mantle diapirs associated with the ascending flow of subduction-induced convection in the mantle wedge and dehydration reactions in the subducting slab (Hasegawa and Zhao, 1994; Iwamori and Zhao, 2000; Zhao et al., 1992, 2010). In the forearc region, the temperature is low; hence magma cannot be produced and the low- $\mathrm{V}$ and high- $\sigma$ zones mainly indicate the existence of fluids. Under the volcanic front and back arc areas, the gradually increased temperature and the continuous occurrence of dehydration down to about $200 \mathrm{~km}$ depth result in partial melting in the mantle wedge. The melt and water incorporated into the upwelling flow either butt up against the bottom of the crust or penetrate into the crust. Figure 6 shows a good spatial correlation between the active arc volcanoes and prominent low- $\mathrm{V}$ anomalies immediately beneath, indicating that magma may pass through along the low- $\mathrm{V}$ zones to form the active volcanoes.

Similar to the Iwaki hypocenter, FNPP is also located above a low-V and high- $\sigma$ anomaly. Based on the above discussion, the anomaly under FNPP may be also associated with the ascending fluids from the subducting Pacific slab. Compared with the high seismicity in the Iwaki source area after the Tohoku-oki earthquake, the seismicity in the FNPP area is relatively low (Fig. 2). The possible reason is that in the FNPP area, reverse faults exist and the horizontal compressional stress there could amount to $\sim 100 \mathrm{MPa}$ (Imanishi et al., 2011). The static stress transfer induced by the Tohoku-oki earthquake was estimated to be a few MPa at most, which is too small to alter the stress regime and increase seismicity in the FNPP area. However, the ascending fluids have likely reduced the strength of the faults in the FNPP area, such as the reverse Namie fault (Fig. 1b). The compressional stress regime is therefore expected to continue to build up in the overriding plate in NE Japan, which has potential to cause reactivation of the reverse faults and therein generate large crustal earthquakes, such as the 2008 Iwate-Miyagi earthquake that occurred about $200 \mathrm{~km}$ north of FNPP (Cheng et al., 2011) and the 2007 Niigata earthquake (M 6.8) in the back-arc area of NE Japan (Xia et al., 2008). Therefore, much attention should be paid to the FNPP seismic safety in the near future.

\section{Supplementary material related to this article is available online at: http://www.solid-earth.net/3/43/2012/ se-3-43-2012-supplement.pdf.}

Acknowledgements. We thank the data center of the JMA Unified Catalogue for providing the high-quality seismic data used in this study. This work was partially supported by the Global-COE program of Earth and Planetary Sciences, Tohoku University, and a research grant (Kiban-S 11050123) from Japan Society for the Promotion of Science to D. Zhao. The figures were made using GMT (Wessel and Smith, 1998). J. van Hunen (the editor), L. Boschi and an anonymous referee provided thoughtful review comments that have improved the manuscript.

Special Issue: "Subduction zones"

Edited by: S. Buiter, F. Funiciello, and J. van Hunen

\section{References}

Asano, Y., Saito, T., Ito, Y., Shiomi, K., Hirose, H., Matsumoto, T., Aoi, S., Hori, S., and Sekiguchi, S.: Spatial distribution and focal mechanisms of aftershocks of the 2011 off the Pacific coast Tohoku Earthquake, Earth Planet. Space, 63, 669-673, 2011.

Cheng, B., Zhao, D., and Zhang, G.: Seismic tomography and anisotropy in the source area of the 2008 Iwate-Miyagi earthquake (M 7.2), Phys. Earth Planet. Inter., 184, 172-185, 2011.

Gupta, S., Zhao, D., Ikeda, M., Ueki, S., and Rai, S.: Crustal tomography under the Median Tectonic Line in Southwest Japan using P and PmP data, J. Asian Earth Sci., 35, 377-390, 2009.

Hasegawa, A. and Zhao, D.: Deep structure of island arc magmatic regions as inferred from seismic observations, Magmatic Systems (edited by M. Ryan), Academic Press, 179-195, 1994.

Huang, Z., Zhao, D., and Wang, L.: Seismic heterogeneity and anisotropy of the Honshu arc from the Japan Trench to the Japan Sea, Geophys. J. Int., 184, 1428-1444, 2011.

Imanishi, K., Ando, R., and Kuwahara, Y.: A generation mechanism of normal-faulting earthquakes in northeast Japan, activated after the 2011 Tohoku earthquake, Japan Geoscience Union 2011 annual meeting, MIS036-P108, 2011.

Ishiyama, T., Sato, H., Sugito, N., Echigo, T., Ito, T., Kato, N., and Imaizumi, T.: Tectonic setting of coseismic surface rupture associated with the 2011 Iwaki earthquake, Japan Geoscience Union 2011 annual meeting, MIS036-P10, 2011.

Iwamori, H. and Zhao, D.: Melting and seismic structure beneath the northeast Japan arc, Geophys. Res. Lett., 27, 425-428, 2000.

Kato, A., Sakai, S., and Obara, K.: A normal-faulting seismic sequence triggered by the 2011 off the Pacific coast of Tohoku 
earthquake: Wholesale stress regime changes in the upper plate, Earth Planet. Space, 63, 745-748, 2011.

Okada, T., Yoshida, K., Ueki, S., Nakajima, J., Uchida, N., Matsuzawa, T., Umino, N., Hasegawa, A., and Group for the aftershock observations of the 2011 off the Pacific coast of Tohoku Earthquake: Shallow inland earthquakes in NE Japan possibly triggered by the 2011 off the Pacific coast of Tohoku Earthquake, Earth Planet. Space, 63, 749-754, 2011.

Padhy, S., Mishra, O. P., Zhao, D., and Wei, W.: Crustal heterogeneity in the 2007 Noto-Hanto earthquake area and its geodynamical implications, Tectonophysics, 509, 55-68, 2011.

Salah, M. and Zhao, D.: 3-D seismic structure of Kii Peninsula in Southwest Japan: Evidence for slab dehydration in the forearc, Tectonophysics, 364, 191-213, 2003.

Sugito, N., Ishiyama, T., Echigo, T., Sato, H., Kato, N., and Imaizumi, T.: Preliminary report on slip distribution of surface rupture associated with the 2011 Iwaki earthquake, Japan Geoscience Union 2011 annual meeting, MIS036-P1, 2011.

Tong, P., Zhao, D., and Yang, D.: Tomography of the 1995 Kobe earthquake area: comparison of finite-frequency and ray approaches, Geophys. J. Int., 187, 278-302, 2011.

Wang, Z. and Zhao, D.: Seismic images of the source area of the 2004 Mid-Niigata prefecture earthquake in Northeast Japan, Earth Planet. Sci. Lett., 244, 16-31, 2006a.
Wang, Z. and Zhao, D.: Seismic evidence for the influence of fluids on the 2005 west off Fukuoka prefecture earthquake in southwest Japan, Phys. Earth Planet. Inter., 155, 313-324, 2006b.

Wessel, P. and Smith, W.: New, improved version of the Generic Mapping Tools released, Eos Trans. AGU, 79(47), 579, doi:10.1029/98EO00426, 1998.

Xia, S., Zhao, D., and Qiu, X.: The 2007 Niigata earthquake: Effect of arc magma and fluids, Phys. Earth Planet. Inter., 166, 153166, 2008.

Zhao, D., Hasegawa, A., and Horiuchi, S.: Tomographic imaging of $\mathrm{P}$ and $\mathrm{S}$ wave velocity structure beneath northeastern Japan, J. Geophys. Res., 97, 19909-19928, 1992.

Zhao, D., Kanamori, H., Negishi, H., and Wiens, D.: Tomography of the source area of the 1995 Kobe earthquake: evidence for fluids at the hypocenter? Science, 274, 1891-1894, 1996.

Zhao, D., Santosh, M., and Yamada, A.: Dissecting large earthquakes in Japan: Role of arc magma and fluids, Island Arc, 19, 4-16, 2010.

Zhao, D., Huang, Z., Umino, N., Hasegawa, A., and Kanamori, H.: Structural heterogeneity in the megathrust zone and mechanism of the 2011 Tohoku-oki earthquake (Mw 9.0), Geophys. Res. Lett., 38, L17308, doi:10.1029/2011GL048408, 2011. 